\title{
Chronic kidney disease and support provided by home care services: a systematic review
}

Sema K Aydede ${ }^{1 *}$, Paul Komenda ${ }^{2}$, Ognjenka Djurdjev ${ }^{3}$ and Adeera Levin ${ }^{4}$

\begin{abstract}
Background: Chronic diseases, such as chronic kidney disease (CKD), are growing in incidence and prevalence, in part due to an aging population. Support provided through home care services may be useful in attaining a more efficient and higher quality care for CKD patients.

Methods: A systematic review was performed to identify studies examining home care interventions among adult CKD patients incorporating all outcomes. Studies examining home care services as an alternative to acute, post-acute or hospice care and those for long-term maintenance in patients' homes were included. Studies with only a home training intervention and those without an applied research component were excluded.

Results: Seventeen studies (10 cohort, 4 non-comparative, 2 cross-sectional, 1 randomized) examined the support provided by home care services in 15,058 CKD patients. Fourteen studies included peritoneal dialysis (PD), two incorporated hemodialysis (HD) and one included both PD and HD patients in their treatment groups. Sixteen studies focused on the dialysis phase of care in their study samples and one study included information from both the dialysis and pre-dialysis phases of care. Study settings included nine single hospital/dialysis centers and three regional/ metropolitan areas and five were at the national level. Studies primarily focused on nurse assisted home care patients and mostly examined PD related clinical outcomes. In PD studies with comparators, peritonitis risks and technique survival rates were similar across home care assisted patients and comparators. The risk of mortality, however, was higher for home care assisted PD patients. While most studies adjusted for age and comorbidities, information about multidimensional prognostic indices that take into account physical, psychological, cognitive, functional and social factors among CKD patients was not easily available.
\end{abstract}

Conclusions: Most studies focused on nurse assisted home care patients on dialysis. The majority were single site studies incorporating small patient populations. There are gaps in the literature regarding the utility of providing home care to CKD patients and the impact this has on healthcare resources.

Keywords: Chronic kidney disease, Dialysis, Home care services

\section{Background}

The world population is aging and the segment of global population 60 years of age and over is increasing at the fastest pace ever seen in history [1]. The population trends are reflected in the demographic profiles of patients with diseases such as chronic kidney disease (CKD) that are common in the elderly. In Canada, over half of the patients initiating renal replacement therapy (RRT) in 2009 were 65 years of age and older [2]. In Europe, RRT patients

\footnotetext{
* Correspondence: sema.aydede@ubc.ca

'School of Population and Public Health, The University of British Columbia and Provincial Health Services Authority, 700-1380 Burrard Street, Vancouver, BC V6Z 2H3, Canada

Full list of author information is available at the end of the article
}

65 years of age and older had the highest rate of increase in prevalence over the 1992-2005 period [3].

CKD populations, especially elderly end-stage renal disease (ESRD) patients, are faced with multiple medical and social challenges such as having to cope with several comorbidities, physical disability, cognitive impairment and social isolation [4-11]. These medical and social challenges are significant in characterizing the impaired quality of life in CKD patients [12,13]. Quality of life deteriorates as the severity of CKD increases [14]. Home care (HC) services may help CKD patients in coping with these challenges, maintaining their independence and fulfilling their preferences of receiving care at home $[15,16]$. 
Current emphasis on active aging and independence represent a unique opportunity to examine $\mathrm{HC}$ services that are utilized to varying degrees by different patient groups but are considered beneficial especially in chronic conditions [17]. In the case of non-ESRD CKD, the utilization of $\mathrm{HC}$ may vary based on patient's age and comorbidities and, in the case of ESRD, it may vary based on the severity of illness and therapy type. HC services may help in supporting ESRD patients who have chosen conservative care. The independent treatment modalities for ESRD (peritoneal dialysis, PD, and home hemodialysis, HHD), emphasized as viable alternatives to facility-based treatment modalities over the last decade, are less costly to direct service providers, with equivalent or superior patient outcomes and quality of life [18-21]. Patients with ESRD, who are on PD or HHD, however, may utilize more $\mathrm{HC}$ services compared to those who are on a facility-based hemodialysis (HD), partially offsetting cost saving [22,23]. On the other hand, the intensity of $\mathrm{HC}$ services received may reduce the number of hospitalizations and subsequent health system costs [24-26] regardless of the stage of CKD and the type of therapy for ESRD.

In general, $\mathrm{HC}$ services provide support to patients and help them with the daily management of their diseases in their communities. However, a proper characterization and a systematic evaluation of these services within a high risk, resource intense group of patients such as those with CKD have not been undertaken. This systematic review (SR) provides a rigorous account of research evidence on $\mathrm{HC}$ use among those with CKD.

\section{Methods}

\section{Eligibility criteria}

Studies about adult patients with any CKD severity level and a $\mathrm{HC}$ intervention regarding services provided in patients' homes were eligible. Our SR was not restricted to studies that incorporated a comparison group. Studies with interventions related to the market place and working conditions of $\mathrm{HC}$ professionals or organizational underpinnings of $\mathrm{HC}$ organizations were excluded.

In the case of RRT, assisted PD patients could get help from a family member, a friend or a $\mathrm{HC}$ worker. In this $\mathrm{SR}$, studies that focused on assisted PD in general without providing subgroup results for $\mathrm{HC}$ assisted PD patients [27-32] and those that examined home visits for reasons other than direct $\mathrm{HC}$ provision [33-36] were excluded. Unlike assisted PD, HHD is rarely available in an assisted format. One recent study that focused on the feasibility of nocturnal assisted HHD did not provide subgroup results for $\mathrm{HC}$ assisted $\mathrm{HHD}$ patients and, therefore, was not included in our SR [37].

In the case of palliative care, support services for CKD patients could be provided in their home or at a hospice. This study focused on home-based end-of-life care.
Studies that examined palliative care without providing information about the specific services patients received in their community and those that did not separately report on subgroups of patients who received home-based support services [38-42] were excluded from our SR.

The primary outcomes included hospitalizations, admissions to institutional settings, length of stay on independent dialysis modalities for ESRD patients, and outcomes specific to treatment type. As secondary outcomes, mortality, medication management, patient satisfaction, caregiver satisfaction, physical and psychological well-being, health status and quality of life were considered. Studies were not excluded based on outcomes studied.

In general, all types of studies including experimental and observational studies were included. The studies that did not contain an empirical component and those with only training/educational and referral/recommendations types of interventions were excluded.

Given the diversity of $\mathrm{HC}$ services and resource considerations, we concentrated on studies published in English. To balance this limitation, a comprehensive literature search was undertaken. The date range was 1990 (i.e., the early stages of profound changes in healthcare systems that started with shifts away from acute care settings towards home and community care [43]) to present.

\section{Definitions}

CKD was conceptualized as consisting of five stages following the Kidney Disease Outcomes Quality Initiative's definition accepted during the Kidney Disease: Improving Global Outcomes (KDIGO) conference [44]. The definition accepted during the KDIGO conference suggests that CKD could also be classified by treatment type: kidney transplant recipient, CKD independent of dialysis and $\mathrm{CKD}$ on dialysis. These classifications guided the development phase of our SR.

The Federal/Provincial/Territorial Working Group on Home Care's definition, as reported by Health Canada, emphasizes the manner with which $\mathrm{HC}$ helps patients: "An array of services which enables clients, incapacitated in whole or part, to live at home, often with the affect of preventing, delaying or substituting for long-term or acute care alternatives" [45]. The Canadian Home Care Association's definition focuses on the breadth of services covered: "an array of services, provided in the home and community setting, that encompasses health promotion and teaching, curative intervention, end-of-life care, rehabilitation, support and maintenance, social adaptation and integration and support for the family caregiver" [46]. Initially, $\mathrm{HC}$ conceptualization for this SR was guided by these definitions. These conceptualizations were further refined during the course of this study as we attempted to standardize terminology for our SR based on HC services covered in the included studies. 


\section{Information sources}

Studies were identified through electronic databases, web sites, hand searches and consultations with experts in the field. Electronic databases included MEDLINE, EMBASE, CINAHL, PsycINFO, EconLit, Cochrane CENTRAL, Cochrane Methodology Register, Cochrane Database of Systematic Reviews, Centre for Reviews and Dissemination (DARE, HTA and NHS EED), ACP Journal Club and Web of Science (final search for MEDLINE is incorporated in the Appendix; final searches for other databases are available from the corresponding author). The web sites included World Health Organization, Health Canada, Canadian Homecare Association, Canadian Health Research Collection and the health departments of Canadian provinces and territories. The electronic database and web site searches, conducted by a University of British Columbia librarian, were completed on May 24, 2012. Hand searches, completed on September 20, 2013, were coupled with consultations with experts in the field.

\section{Study selection}

We followed a layered approach in study selection. An initial elimination of irrelevant studies was carried out by study assistants independently based on title and abstract reviews using a pre-tested selection form. An author (SKA) checked the initial selection and reviewed the complete texts of potentially relevant studies. The remaining manuscripts were reviewed in full by two additional authors independently (AL and PK). Disagreements were resolved after discussions among authors. Each selected study was summarized using a pre-tested data extraction form and was evaluated using the Agency for Healthcare Research and Quality risk of bias and confounding form developed for observational studies [47].

\section{Analysis}

Due to the heterogeneity of patient populations considered, interventions examined and health outcomes reported in the studies included in our SR, a meta-analysis was not possible. We performed a narrative summary of studies focusing mainly on key outcomes of importance to the CKD community.

\section{Results}

\section{Study selection}

A total of 17 studies were identified for inclusion in the SR. The searches of electronic databases provided a total of 4354 citations (Figure 1) with 185 additional citations identified through hand-searches and author consultations. After adjustments for duplicates and title and abstract screening, a total of 521 full text articles were assessed and 17 were eligible for inclusion.

\section{Study characteristics and patient populations}

Of the 17 studies included in this study (overview of study characteristics in Table 1 and detail on patient populations, $\mathrm{HC}$ interventions and outcomes in Table 2), 14 focused on the impact $\mathrm{HC}$ has on PD patients. Ten of the PD studies were cohort studies [48-57], three were non-comparative [58-60] and one used cross sectional study design [61]. Five national level PD cohort studies $[48,51,52,55,56]$ used information from the French Language Peritoneal Dialysis Registry (RDPLF). Two of these RDPLF studies [51,52] used the same time period but applied different exclusion criteria based on the focus of the studies. Two PD cohort studies [53,54] relied on data from regional dialysis units. The remaining three PD cohort studies $[49,50,57]$ and all of the non-comparative and cross sectional PD studies [58-61] used data from a single hospital/dialysis unit. Of the 14 PD studies, 6 were from France $[48,50-52,55,56], 3$ from Canada [53,54,58], 2 from the United States of America (USA) [60,61] and one each from China [57], Taiwan [49] and Brazil [59].

Of the 17 studies included in this study, 2 studies examined the impact $\mathrm{HC}$ has on $\mathrm{HD}$ patients. One of these studies was a randomized trial [62] conducted in an Iranian hospital and the second one was a non-comparative study that used information from citywide dialysis units in the USA [63].

In contrast to the general trend of studies included in this SR where the focus was exclusively on the dialysis phase of care for patients, one study [64] included information from both the dialysis and pre-dialysis phases of care for PD and HD patients. This study explored the impact $\mathrm{HC}$ has on patients in one hospital in the United Kingdom.

The studies included in this SR examined $\mathrm{HC}$ in a total of 15,058 patients (Table 2). Patients on PD treatment (with a total of 14,954 patients) constituted the dialysis population that was most frequently studied. While most studies focused on general dialysis populations, two PD studies [58,60] and one HD study [63] examined HC in special dialysis populations that had severe disability, terminal illness or complex comorbid conditions.

Of the 17 studies included in this review, 3 focused on elderly patients $[48,49,53]$ with average age of the study samples ranging from 73 years [49] to 82 years [48]. In the remaining studies with pertinent information, average age ranged from 55 years [56,61] to 69 years [63]. The PD studies with comparators and pertinent information revealed that $\mathrm{HC}$ assisted PD patients had a higher average age ranging from 71 years [57] to 83 years [48] when compared to the overall age of study samples.

\section{Home care intervention}

$\mathrm{HC}$ interventions primarily focused on the assistance provided during dialysis treatment (Table 2). The two studies 


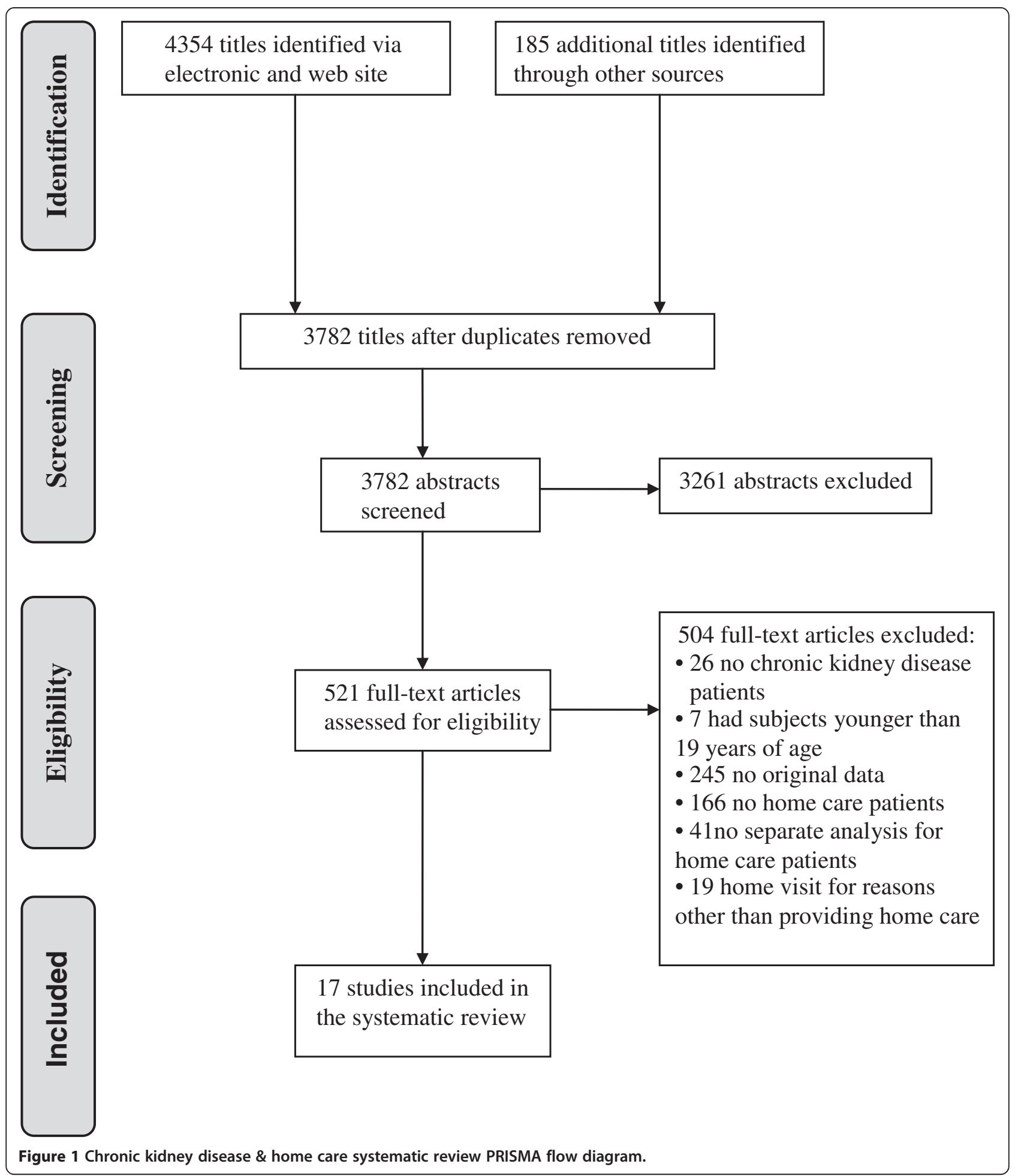

that examined $\mathrm{HC}$ interventions for $\mathrm{HD}$ patients $[62,63]$ and most of the $\mathrm{HC}$ assisted PD studies [48,50-53,55, $56,58,60]$ focused on assistance dialysis patients received from a nurse. Two of the remaining studies [61,64] considered the effects of $\mathrm{HC}$ teams and the rest focused on assistance received from either a home-assistant where a background in healthcare was not necessary [49,57], a nurse assistant [59] or a nurse or a healthcare aid [54].

There are several factors, such as the severity of illness, the scope of $\mathrm{HC}$ provision and the requirements of dialysis 
Table 1 Overview of study characteristics

\begin{tabular}{|c|c|c|c|}
\hline Study & Type of study & Setting, data source $\&$ data period & Country \\
\hline \multicolumn{4}{|l|}{ Peritoneal dialysis } \\
\hline \multirow[t]{2}{*}{ Brunier et al. [58] } & Non-Comparative (Case Series) & • Hospital & Canada \\
\hline & & - Sunnybrook Health Science Centre (November 1993 - May 1995) & \\
\hline \multirow[t]{2}{*}{ Castrale et al. [48] } & Retrospective Cohort & - National & France \\
\hline & & • French Peritoneal Dialysis Registry Data (January 2000 - December 2007) & \\
\hline \multirow[t]{2}{*}{ Franco et al. [59] } & Non-Comparative (Case Series) & - Clinic & Brazil \\
\hline & & • GAMEN Renal Clinic (January 2003- July 2009) & \\
\hline \multirow[t]{2}{*}{ Hsieh et al. [49] } & Prospective Cohort & • Hospital & Taiwan \\
\hline & & • Chang Gung Memorial (January 2000 - December 2009) & \\
\hline \multirow[t]{2}{*}{ Lobbedez et al. [50] } & Retrospective Cohort & - Hospital & France \\
\hline & & - Academic Hospital of Basse-Normandie (1 January 1998-31 December 2003) & \\
\hline \multirow[t]{2}{*}{ Lobbedez et al. [51] } & Retrospective Cohort & - National & France \\
\hline & & - French Peritoneal Dialysis Registry Data (1 January 2002 - 1 June 2011) & \\
\hline \multirow[t]{2}{*}{ Lobbedez et al. [52] } & Retrospective Cohort & • National & France \\
\hline & & - French Peritoneal Dialysis Registry Data (1 January 2002 - 1 June 2011) & \\
\hline \multirow[t]{2}{*}{ Oliver et al. [53] } & Prospective Cohort & - Regional Dialysis Center & Canada \\
\hline & & - Sunnybrook Health Science Centre (1 January 2004-25 May 2006) & \\
\hline \multirow[t]{2}{*}{ Oliver et al. [54] } & Prospective Cohort & - 4 Regional Dialysis Centers & Canada \\
\hline & & $\begin{array}{l}\text { - Sunnybrook Health Science Centre (HSC), Halton Healthcare, London } \\
\text { HSC, Manitoba Renal Program (January } 2004 \text { - January 2009) }\end{array}$ & \\
\hline \multirow[t]{2}{*}{ Ponferrada et al. [61] } & Cross Sectional (Survey) & - Dialysis Unit & USA \\
\hline & & - Dialysis Clinic Inc (Data period not reported) & \\
\hline \multirow[t]{2}{*}{ Verger et al. [55] } & Retrospective Cohort & - National & France \\
\hline & & • French Peritoneal Dialysis Registry Data (1 January 1995-1 January 2006) & \\
\hline \multirow[t]{2}{*}{ Verger et al. [56] } & Retrospective Cohort & - National & France \\
\hline & & • French Peritoneal Dialysis Registry Data (1 January 2000 - 1 January 2005) & \\
\hline \multirow[t]{2}{*}{ Wadhwa et al. [60] } & Non-Comparative (Case Series) & • Hospital & USA \\
\hline & & $\begin{array}{l}\text { - Division of Nephrology and Hypertension - State University of New } \\
\text { York (January } 1989 \text { - December 1992) }\end{array}$ & \\
\hline \multirow[t]{2}{*}{ Xu et al. [57] } & Prospective Cohort & - Hospital & China \\
\hline & & • Peking University First Hospital (July 2002 - April 2010) & \\
\hline \multicolumn{4}{|l|}{ Hemodialysis } \\
\hline \multirow[t]{2}{*}{ Agraharkar et al. [63] } & Non-Comparative (Case Series) & - Citywide & USA \\
\hline & & - Dialysis centers in the greater Houston area (1995-1998) & \\
\hline \multirow[t]{2}{*}{ Babamohammadi et al. [62] } & Randomized controlled trial & • Hospital & Iran \\
\hline & & - Fatemyeh Hospital (Data period not reported) & \\
\hline \multicolumn{4}{|l|}{ Pre-dialysis \& dialysis } \\
\hline \multirow[t]{2}{*}{ Wilde et al. [64] } & Cross Sectional (Survey) & - Hospital & UK \\
\hline & & - Leicester General Hospital (Data period not reported) & \\
\hline
\end{tabular}

technique used, that will influence the characteristics of a HC intervention. While patients on continuous cycling PD (CCPD) will mostly require two visits per day, those on continuous ambulatory PD (CAPD) may require one to four visits based on the severity of their disability $[56,58]$. The time that a $\mathrm{HC}$ worker spends at a CAPD patient's home is dependent on the CAPD system used. PD exchange help for a patient on an ultraviolet non-disconnect CAPD system will usually require less time (about 10-15 minutes) compared to the time (about 30-45 minutes) needed for a patient on a double-bag disconnect CAPD system [55]. 
Table 2 Patient population, intervention type and major findings of studies

\begin{tabular}{|c|c|c|c|c|}
\hline Study & Number of patients & Mean age & Type of home care intervention & Major findings \\
\hline \multicolumn{5}{|l|}{ Peritoneal dialysis } \\
\hline \multirow[t]{8}{*}{ Brunier et al. [58] } & \multirow[t]{8}{*}{$\cdot 18 \mathrm{HC}$ assisted $\mathrm{PD}^{\mathrm{a}}$} & \multirow[t]{8}{*}{$\cdot 61$} & \multirow{8}{*}{$\begin{array}{l}\text { - HC }{ }^{\beta} \text { (Nurse) assisted PD: Publicly funded program } \\
\text { where nurses visit homes for PD exchanges and } \\
\text { clinical and social support } \\
\text { - } \text { CAPD }^{\gamma} \text { required } 1-4 \text { visits / day based on severity } \\
\text { of disability } \\
\text { - } \text { CCPD }^{\delta} \text { required } 2 \text { visits / day } \\
\text { - Reporting on } 3 \text { years of experience }\end{array}$} & Peritonitis Rate: \\
\hline & & & & - One episode of peritonitis per 33.8 \\
\hline & & & & $\begin{array}{l}\text { white blood and } 1 \text { AIDS patient); if } \\
\text { included, one episode of peritonitis }\end{array}$ \\
\hline & & & & per 20.1 patients-months \\
\hline & & & & Hospitalization Rate: \\
\hline & & & & $\begin{array}{l}\text { - One hospital admission per } 15.3 \\
\text { patient-months (excluding } 5 \text { palliative } \\
\text { care patients) }\end{array}$ \\
\hline & & & & Costs: \\
\hline & & & & $\begin{array}{l}\text { - Annual costs were } \$ 27,263 \text { for home } \\
\text { CAPD, } \$ 29,763 \text { for home CCPD and } \\
\$ 29,915 \text { for HD } \mathrm{HD}^{\varepsilon}\end{array}$ \\
\hline \multirow[t]{7}{*}{ Castrale et al. [48] } & \multirow{2}{*}{$\begin{array}{l}\cdot 1232 \mathrm{HC} \text { assisted PD } \\
\text { • } 87 \text { Family assisted PD }\end{array}$} & \multirow{7}{*}{$\begin{array}{l}\cdot 83 \text { (HC assisted PD) } \\
\cdot 81 \text { (Family assisted PD) } \\
\cdot 80 \text { (Self care PD) } \\
\text { * Elderly }\end{array}$} & \multirow{7}{*}{$\begin{array}{l}\text { - HC (Nurse) assisted PD: Publicly funded home } \\
\text { visits by private sector nurses for assisted PD } \\
\text { - Study end point allowed for at least } 2 \text { years of } \\
\text { follow-up for patients who are on PD continuously } \\
\text { (Frequency of visits not reported) }\end{array}$} & Peritonitis Rate: \\
\hline & & & & \multirow{2}{*}{$\begin{array}{l}\text { - Compared to self care PD, HC } \\
\text { (nurse) assisted PD had similar risks } \\
\text { of peritonitis rates (Bivariate results) }\end{array}$} \\
\hline & \multirow[t]{5}{*}{ • 294 Self care PD } & & & \\
\hline & & & & Patient Survival: \\
\hline & & & & $\begin{array}{l}\text { - Compared to self care PD, HC } \\
\text { (nurse) assisted PD was associated } \\
\text { with a higher risk of mortality } \\
\left(\mathrm{RH}^{\zeta}=2.35\right)\end{array}$ \\
\hline & & & & Technique Survival: \\
\hline & & & & $\begin{array}{l}\text { - Compared to self care PD, HC (nurse) } \\
\text { assisted PD had similar risks of } \\
\text { technique failure (=transfer to HD) }\end{array}$ \\
\hline \multirow[t]{4}{*}{ Franco et al. [59] } & \multirow[t]{4}{*}{ • $30 \mathrm{HC}$ assisted PD } & \multirow[t]{4}{*}{ • 72 (Median) } & \multirow{3}{*}{$\begin{array}{l}\text { - HC (Nurse Assistant) assisted PD: Home visits by } \\
\text { nurse assistants for assisted PD } \\
\text { - Study end point allowed for at least } 16 \text { months } \\
\text { of follow-up for patients who are on PD } \\
\text { continuously (Frequency of visits not reported) }\end{array}$} & Peritonitis Rate: \\
\hline & & & & $\begin{array}{l}\text { - One episode of peritonitis per } 37 \\
\text { patient-months }\end{array}$ \\
\hline & & & & Patient Survival: \\
\hline & & & - Each nurse assistant was responsible for 4 patients & $\begin{array}{l}\text { - Patient survival was } 60 \% \text { at } 12 \\
\text { months, } 23 \% \text { at } 24 \text { month, } 3 \% \text { at } \\
48 \text { months }\end{array}$ \\
\hline
\end{tabular}


Table 2 Patient population, intervention type and major findings of studies (Continued)

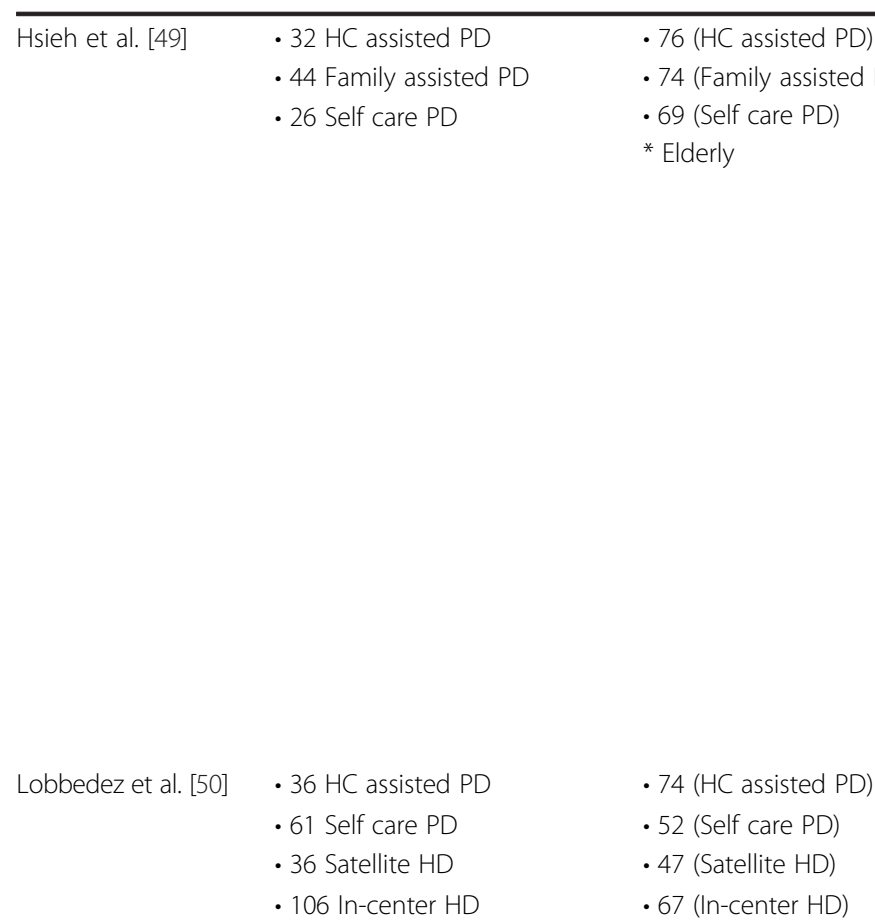

- HC (Home Assistant) assisted PD: Home assistants Peritonitis Rate:

(a background in healthcare was not required)

paid by the family assisted with PD.

- HC assisted PD patients followed for 93 to

1832 days (Frequency of visits not reported)

- Peritonitis rates of 1 episode per

24 (HC-home assistant-assisted PD),

37 (family assisted PD) and 39 (self PD)

patient months were not significantly

different

- Probability of a 12 month peritonitis-free

periods of $62.5 \%$ (HC-home

assistant-assisted PD), 75.0\% (family

assisted PD) and 80.8\% (self PD) were

not significantly different

Patient Survival:

- Peritonitis-related deaths of 13.8\% (HC-home assistant-assisted PD), 8.0\% (family assisted PD)

and $8.0 \%$ (self PD) were not significantly different

Technique Survival:

- Following peritonitis, technique failures of 34.5\% (HC-home assistant-assisted PD), 16.0\% (family assisted PD) and 16.0\% (self PD) were not significantly different

PD Eligibility/Utilization/Uptake:

- HC (nurse) assisted PD enables increased use of PD in incident dialysis patients

Peritonitis Rate:

- HC (nurse) assisted PD patients: Actuarial survival free of peritonitis was $72 \%$ at

6 months, $50 \%$ at 12 months

Hospitalization Rate:

- HC (nurse) assisted PD patients:

- Actuarial survival free of hospitalization $46 \%$ at 6 months, $21 \%$ at 12 months

- Hospitalization rate was 0.4 admissions/ patient/month

Technique Survival:

- HC (nurse) assisted PD patients: Technique survival $85 \%$ at 6 months, $58 \%$ at 12 month

Charlson Comorbidity Index:

- Charlson Comorbidity Index higher for HC (nurse) assisted PD (7.0) when compared to self care PD (4.3) and similar when compared to in-center HD (7.7) 
Table 2 Patient population, intervention type and major findings of studies (Continued)

\begin{tabular}{|c|c|c|c|}
\hline \multirow[t]{5}{*}{ Lobbedez et al. [51] } & - $4230 \mathrm{HC}$ assisted PD & \multirow{3}{*}{$\begin{array}{l}\text { • } 79 \text { (Median, HC assisted PD) } \\
\text { • } 74 \text { (Median, Family assisted } \\
\text { PD) }\end{array}$} & \multirow{2}{*}{$\begin{array}{l}\text { - HC (Nurse) assisted PD: Publicly funded home } \\
\text { visits by private sector nurses for assisted PD }\end{array}$} \\
\hline & • 1056 Family PD & & \\
\hline & - 4515 Self care PD & & \multirow{2}{*}{$\begin{array}{l}\text { - Study end point allowed for at least } 5 \text { months } \\
\text { of follow-up for patients who are on PD } \\
\text { continuously (Frequency of visits not reported) }\end{array}$} \\
\hline & & • 56 (Median, Self care PD) & \\
\hline & & & $\begin{array}{l}\text { • Interquartile range of PD duration } 7.78 \text { to } \\
29.70 \text { months }\end{array}$ \\
\hline
\end{tabular}

Patient Survival:

- Compared to self care PD, HC (nurse) assisted PD was associated with a higher risk of mortality $\left(\mathrm{Cs}-\mathrm{RH}^{\mathrm{n}}=4.52\right)$

- Compared to self care PD + family assisted PD, $\mathrm{HC}$ (nurse) assisted PD was associated with a higher risk of mortality (cs-RH=2.18)

\section{Technique Survival:}

- Compared to self care PD, HC (nurse) assisted PD was associated with a lower risk of technique failure (=transfer to $\mathrm{HD}, \mathrm{cs}-\mathrm{RH}=0.84, \mathrm{sd}^{-} \mathrm{RH}^{\ominus}=0.72$ )

- Compared to self care PD + family assisted PD, HC (nurse) assisted PD was associated with a lower risk of technique failure (=transfer to $\mathrm{HD}, \mathrm{cs}-\mathrm{RH}=0.85, \mathrm{sd}-\mathrm{RH}=0.72$ )

Renal Transplantation:

- Compared to self care PD, HC (nurse) assisted PD was associated with a lower risk of renal transplantation (cs- $\mathrm{RH}=0.04)$

- Compared to self care PD + family assisted PD, HC (nurse) assisted PD was associated with a lower risk of renal transplantation (cs-RH $=0.16$ )

Renal Recovery:

- Compared to self care PD, HC (nurse) assisted PD was associated with a similar risk of renal recovery (Bivariate results)

- Compared to self care PD + family assisted PD, HC (nurse) assisted PD was associated with a similar risk of renal recovery

- HC (Nurse) assisted PD: Publicly funded home . 3891 Self care PD Start) visits by private sector nurses for assisted PD

*Additional exclusions compared o Lobbedez et al., 2012 to focus on sub-optimal PD starts

69 (Median, Sub-optimal PD Start)
Study end point allowed for at least 5 months of follow-up for patients who are on PD continuously (Frequency of visits not reported)

- Interquartile range of PD duration 8.08 to 29.99 months

\section{Peritonitis Rate:}

Compared to self care PD, HC (nurse) assisted PD was associated with a lower risk of peritonitis $(\mathrm{sd}-\mathrm{RH}=0.81)$ Patient Survival:

- Compared to self care PD, HC (nurse) assisted PD was associated with a higher risk of mortality $(\mathrm{sd}-\mathrm{RH}=6.30$ )

Technique Survival:

- Compared to self care PD, HC (nurse) assisted PD was associated with a lower risk of technique failure (=transfer to $\mathrm{HD}, \mathrm{sd}-\mathrm{RH}=0.67$ )

Renal Transplantation:

- Compared to self care PD, HC (nurse) assisted PD was associated with a lower risk of renal transplantation (sd- $\mathrm{RH}=0.03$ ) (Bivariate results) 
Table 2 Patient population, intervention type and major findings of studies (Continued)

Oliver et al. [53]

- $22 \mathrm{HC}$ assisted PD

- 4 Self care PD

- 16 In-center HD

. 76 (Median, HC assisted PD)

- 76 (Median, Other

Modalities)

*Elderly

. 66 (Overall)

- 8 Family and $\mathrm{HC}$ assisted PD

- 1 Friend assisted PD

- 26 Family assisted PD

. 56 Self care PD

Ponferrada et al. [61] • $36 \mathrm{HC}$ assisted PD
- HC (Nurse) assisted PD: Publicly funded program where nurses visit homes for PD exchanges and clinical and social support

- First year of dialysis, HC assisted PD patients received, on average, 5.8 visits / week

- HC assisted PD patients offered 2 visits / day 7 days a week

- Mean follow-up for HC assisted PD patients were 413 days

- HC (Nurse or Healthcare Aid) assisted PD: Publicly funded program where nurses or healthcare aids visit homes for assisted PD

- Maximum 2 nurse or healthcare aid visits/day - Mean (median) follow-up for PD patients were 521 (376) days

- HC (Team) assisted PD: Home visits by home care team (nurse, dietician \& social worker) for assisted PD and patient assessments

- Reporting on evaluation over a 18-month period

- Study recommendations: One routine visit for new patients and additional non-routine visits only if there are significant problems

- A visit took approximately 4 hours
PD Eligibility/Utilization/Uptake:

- More elderly patients were considered eligible for PD $\left(\mathrm{OR}^{\mathrm{l}}=2.6\right)$ if they lived in a $\mathrm{HC}$ support region than if they did not

Hospitalization Rate \& Days:

- Hospitalization rate was not significantly different between HC (nurse) assisted PD (1.4 per patient-year) and other modalities (1.0 per patient-year)

- Hospital days were not significantly different between HC (nurse) assisted PD (23.5 per patient-year) and other modalities (13.1 per patient-year)

Patient Survival:

- Mortality was not significantly different between HC

(nurse) assisted PD (0.12 per patient-year) and

other modalities ( 0.18 per patient-year)

Technique Survival:

Modality changes were not significantly different between HC (nurse) assisted PD (0.04 per patient-year) and other modalities (0.19 per patient-year)

PD Eligibility/Utilization/Uptake:

- Even when HC (nurse or healthcare aid) assisted PD is available, family support remains to be an important driver of PD utilization.

- Among patients with barriers to PD who live in areas with HC assisted PD availability, PD utilization was higher (39\%) among those who had family support compared to those without family support (23\%)

Critical Elements of Home Visits:

- Dialysis programs should retain the option of making home visits to home dialysis patients

- To evaluate internal policy and identify critical

elements of a home visit 
Table 2 Patient population, intervention type and major findings of studies (Continued)

\begin{tabular}{|c|c|c|c|}
\hline \multirow[t]{4}{*}{ Verger et al. [55] } & • 5284 HC assisted PD & \multirow[t]{4}{*}{ • 66 (Overall) } & \multirow{4}{*}{$\begin{array}{l}\text { - HC (Nurse) assisted PD: Publicly funded home } \\
\text { visits by private sector nurses for assisted PD } \\
\text { - Nurse time at patient's home for: a) non-disconnect } \\
\text { CAPD ultraviolet system between } 10-15 \text { minutes, } \\
\text { and b) double-bag disconnect CAPD system } \\
\text { between } 30-45 \text { minutes (Frequency of visits } \\
\text { not reported) }\end{array}$} \\
\hline & • 822 Family assisted PD & & \\
\hline & • 8285 Self care PD & & \\
\hline & • 352 Other / Undefined PD & & \\
\hline \multirow[t]{4}{*}{ Verger et al. [56] } & • 232 HC assisted PD & • 73 (HC assisted PD) & \multirow{2}{*}{$\begin{array}{l}\text { - HC (Nurse) assisted PD: Publicly funded home } \\
\text { visits by private sector nurses for assisted PD }\end{array}$} \\
\hline & - 127 Family assisted PD & - 65 (Family assisted PD) & \\
\hline & • 1265 Self care PD & • 51 (Self care PD) & \multirow{2}{*}{$\begin{array}{l}\text { - Study end point allowed for at least } 13 \text { months } \\
\text { of follow-up for patients who are on PD continuousl } \\
\text {-1-2 nurse visits / day }\end{array}$} \\
\hline & *Automated PD patients only & & \\
\hline \multirow[t]{2}{*}{ Wadhwa et al. [60] } & \multirow[t]{2}{*}{ - $21 \mathrm{HC}$ assisted PD } & \multirow[t]{2}{*}{$\cdot 62$} & $\begin{array}{l}\text { - HC (Nurse) assisted PD: Home visits by nurses for } \\
\text { assisted PD and clinical support }\end{array}$ \\
\hline & & & $\begin{array}{l}\text { - Mean number of nursing hours per day was } 13 \\
\text { (Frequency of visits not reported) }\end{array}$ \\
\hline \multirow[t]{3}{*}{ Xu et al. [57] } & • $36 \mathrm{HC}$ assisted PD & • 71 (HC assisted PD) & \multirow{3}{*}{$\begin{array}{l}\text { - HC (Home Assistant) assisted PD: Home assistants } \\
\text { (a healthcare background was not required) paid } \\
\text { by the family assisted with PD } \\
\text { - PD patients followed for } 1 \text { to } 88 \text { months } \\
\text { (Frequency of visits not reported) }\end{array}$} \\
\hline & - 86 Family assisted PD & - 66 (Family assisted PD) & \\
\hline & - 191 Self care PD & - 55 (Self care PD) & \\
\hline
\end{tabular}

PD Eligibility/Utilization/Uptake:

- Provides a description of the PD population

- Over the decade studied, $45 \%$ of all incident PD patients received $\mathrm{HC}$ (nurse) assisted PD and $87 \%$ of incident PD patients over 90 years of age received HC (nurse) assisted PD

Charlson Comorbidity Index:

- Among prevalent PD patients, Charlson comorbidity index, on average, was 7.6 for HC (nurse) assisted PD, 6.6 for family assisted PD and 4.8 for self care PD

Peritonitis Rate:

- The probability of being peritonitis free at 24 months better for family assisted PD (76.7\%) compared to HC

(nurse) assisted PD (41.2\%) when nurse visits from dialysis centers are not considered

- The probability of being peritonitis free at 24 months similar between family assisted PD (57.7\%) and HC (nurse) assisted PD (60.7\%) when nurse visits from dialysis centers are considered

- For HC (nurse) assisted PD, the probability of being peritonitis free better for those affiliated with dialysis centers with nurse visits

- For family assisted PD, the probability of being peritonitis free similar across centers with and without nurse visits

\section{Peritonitis Rate:}

- One episode of peritonitis per 13 patient-months Hospitalization Rate \& Days:

- One hospital admission per 6 patient-months

- Mean hospitalization days of 9 per admission Peritonitis Rate:

- First episode of peritonitis was not significantly different between HC (home assistant) assisted PD and family assisted PD

Patient Survival:

- Compared to family assisted PD, HC (home assistant) assisted PD was associated with higher risk of mortality $(H R=2.14)$

Technique Survival:

- Technique survival was not significantly different between HC (home assistant) assisted PD (69.8 months) and family assisted PD (74.8 months) 
Table 2 Patient population, intervention type and major findings of studies (Continued)

\begin{tabular}{lll}
\hline Hemodialysis & $\cdot 69$ \\
Agraharkar et al. [63] & $\cdot 28 \mathrm{HC}$ assisted HD & \\
& & \\
& & \\
Babamohammadi & $\cdot 19 \mathrm{HC}$ assisted HD & $\cdot 56$ (HC assisted HD) \\
et al. [62] & $\cdot 18 \mathrm{HD}$ without HC & $\cdot 58$ (HD without HC)
\end{tabular}

\section{Pre-dialysis \& Dialysis}

Wilde et al. [64] $\quad$ • $57 \mathrm{HC}$ assisted PD or HD $\quad$ • Not described

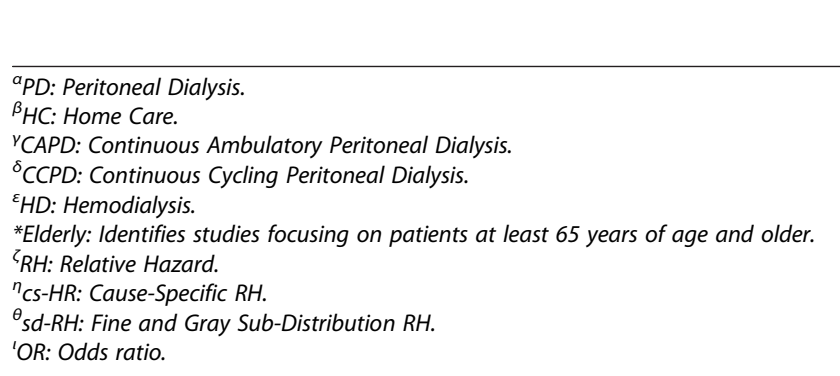

- HC (Nurse) Assisted HD: Home visit by registered nurse for dialysis and clinical support

- Nephrologists also made home visits

- HD patients followed for 2 to 71 weeks

- Frequency of visits determined by the nephrologist upon patient's discharge from the hospital

- HC (Nurse) Assisted HD: Visits every week before HD schedule for clinical support and retraining

- Mean follow-up for HC assisted HD patients were 27.1 months

.4 visits / month
Hospital Days:

- Mean hospitalization days of $9.43+/-1.83$

Costs:

- Weekly ongoing costs of $\mathrm{HC}$ (nurse) assisted HD were $\$ 1200$, in-center HD with ambulance transportation were $\$ 2640$ and in-hospital dialysis were \$5241

\section{Clinical Outcomes:}

15 out of the 19 items studied improved for home care group (weight gain, nausea, vomiting, headache, bone pain, weakness and fatigue, and itching decreased and general condition and levels of BUN, creatinine, potassium and phosphorus of the blood improved significantly. Changes in the mean values of blood pressure, pulse, temperature, sodium and calcium and hematocrit were not significant)

- HC (Team): Home care team (3 nurses \& 1 renal care assistant) visits during pre-dialysis and dialysis phase of care for PD and HD patients

- Visits until transplantation, switch to hospital-based dialysis or death (Frequency of visits not reported)

\section{Satisfaction with Home Care:}

Overall satisfaction with home care program: a) pre-dialysis phase of care $-76 \%$ very satisfied, $20 \%$ partly satisfied and $b$ ) dialysis phase of care $-80 \%$ very satisfied, $20 \%$ partly satisfied 
Table 3 Risk of bias and confounding

Risk of bias and confounding

Q1: Do the inclusion/exclusion criteria remain identical across the comparison groups (the individuals) of the study?

\begin{tabular}{|c|c|c|}
\hline \multirow{2}{*}{$\begin{array}{l}\text { Peritoneal } \\
\text { Dialysis }\end{array}$} & Yes & Castrale [48], Franco [59], Hsieh [49], Lobbedez [51,52], Verger [55,56], Xu [57] \\
\hline & Partially & Brunier [58], Lobbedez [50], Oliver [53,54], Ponferrada [61], Wadhwa [60] \\
\hline Hemodialysis & Yes & Agraharkar [63], Babamohammadi [62] \\
\hline $\begin{array}{l}\text { Pre-dialysis \& } \\
\text { Dialysis }\end{array}$ & No & Wilde [64] \\
\hline
\end{tabular}

Q2: Does the strategy for recruiting participants into the study remain identical across groups (individuals)?

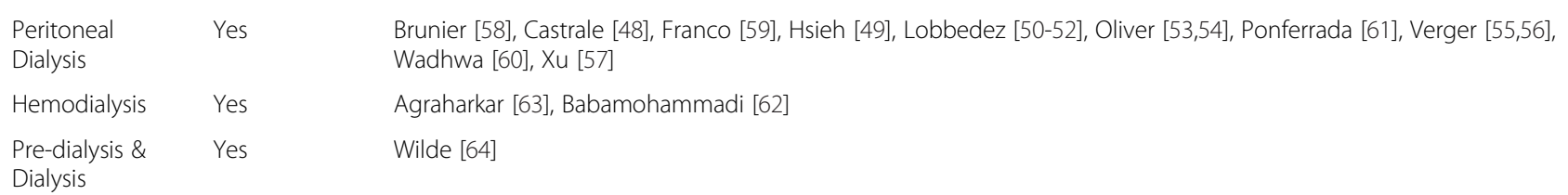
Dialysis

Q3: Is the selection of the comparison group appropriate, after taking into account feasibility and ethical considerations?

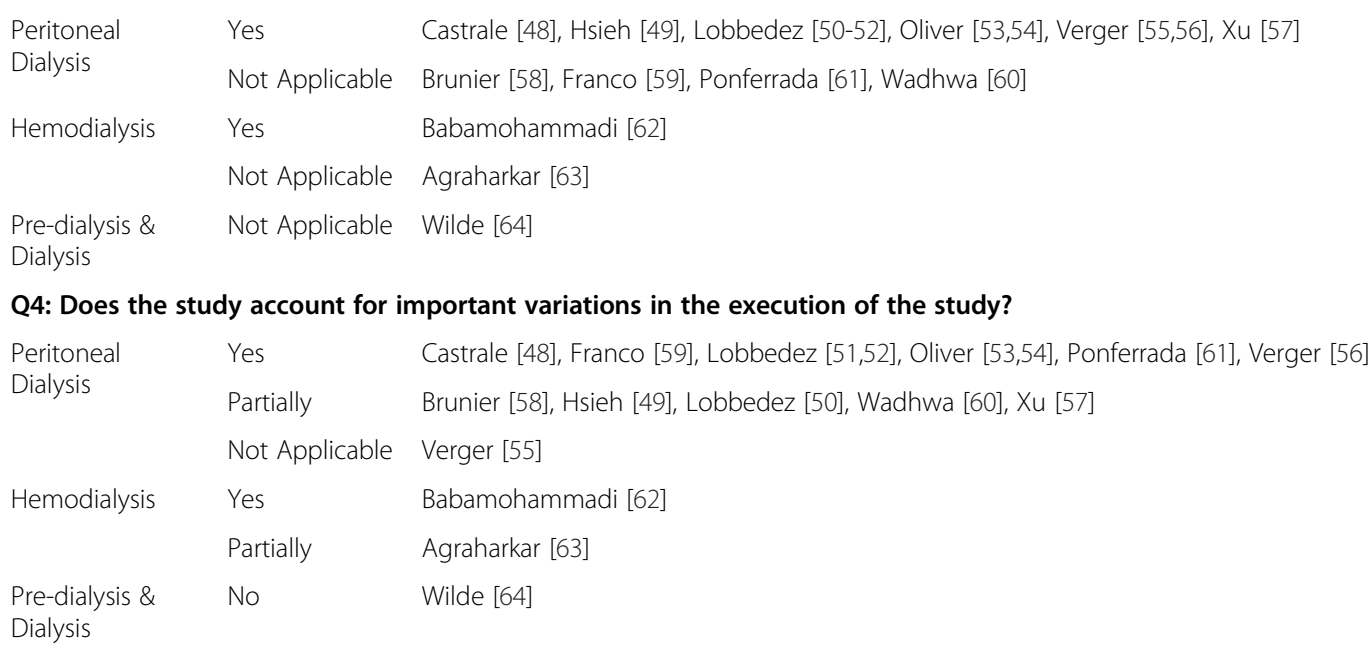

Q5: Were valid and reliable measures, implemented consistently across all study participants used to assess inclusion/exclusion criteria, intervention/exposure outcomes, participant benefits and harms, and potential confounders?

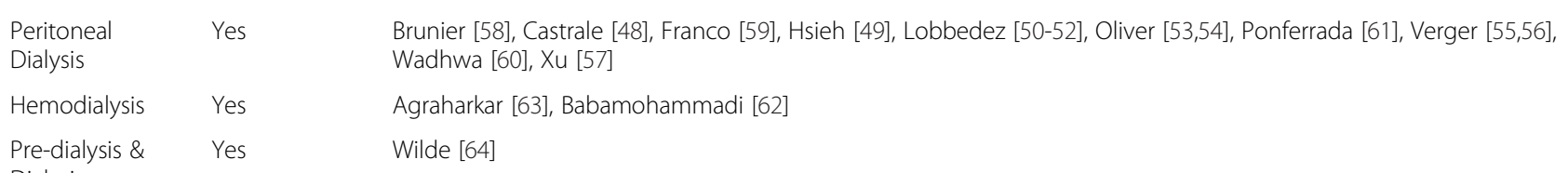
Pre-dialysis \& Yes Wilde [64]

Q6: Was the length of follow-up identical across study groups or remedied through analysis?

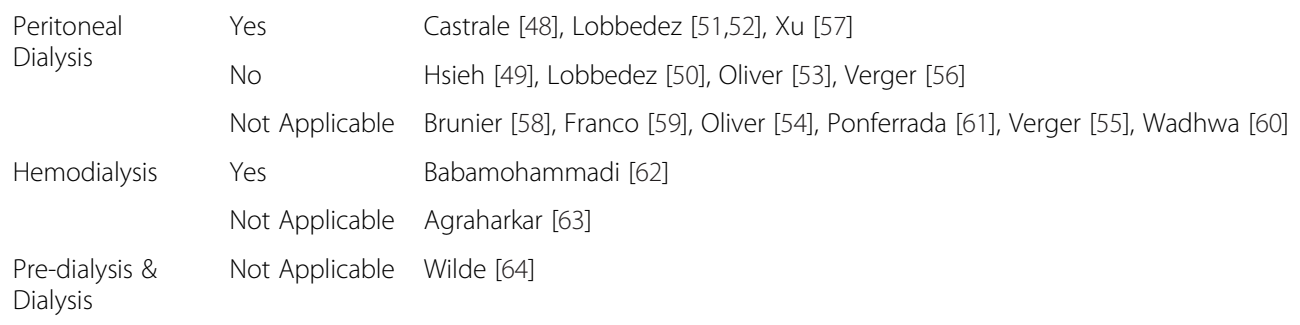

Q7: In cases of high loss to follow-up (or differential loss to follow-up), was the impact assessed (e.g., through sensitivity analysis or other adjustment method)?

$\begin{array}{lll}\begin{array}{l}\text { Peritoneal } \\ \text { Dialysis }\end{array} & \text { Yes } & \text { Lobbedez [51,52] } \\ & \text { No } & \text { Brunier [58], Oliver [53], Wadhwa [60] } \\ & \text { Not Applicable } & \text { Oliver [54], Ponferrada [61], Verger [55] }\end{array}$


Table 3 Risk of bias and confounding (Continued)

\begin{tabular}{|c|c|c|}
\hline & $\begin{array}{l}\text { Cannot } \\
\text { Determine }\end{array}$ & Castrale [48], Franco [59], Hsieh [49], Lobbedez [50], Verger [56], Xu [57] \\
\hline Hemodialysis & $\begin{array}{l}\text { Cannot } \\
\text { Determine }\end{array}$ & Agraharkar [63], Babamohammadi [62] \\
\hline $\begin{array}{l}\text { Pre-dialysis \& } \\
\text { Dialysis }\end{array}$ & No & Wilde [64] \\
\hline \multicolumn{3}{|c|}{ Q8: Are all important primary outcomes accounted for in the results? } \\
\hline $\begin{array}{l}\text { Peritoneal } \\
\text { Dialysis }\end{array}$ & Yes & $\begin{array}{l}\text { Brunier [58], Castrale [48], Franco [59], Hsieh [49], Lobbedez [50-52], Oliver [53,54], Ponferrada [61], Verger [55,56], } \\
\text { Wadhwa [60], Xu [57] }\end{array}$ \\
\hline \multirow[t]{2}{*}{ Hemodialysis } & Yes & Babamohammadi [62] \\
\hline & Partially & Agraharkar [63] \\
\hline $\begin{array}{l}\text { Pre-dialysis \& } \\
\text { Dialysis }\end{array}$ & Yes & Wilde [64] \\
\hline \multicolumn{3}{|c|}{ Q9: Are results believable taking study limitations into consideration? } \\
\hline $\begin{array}{l}\text { Peritoneal } \\
\text { Dialysis }\end{array}$ & Yes & $\begin{array}{l}\text { Brunier [58], Castrale [48], Franco [59], Hsieh [49], Lobbedez [50-52], Oliver [53,54], Ponferrada [61], Verger [55,56], } \\
\text { Wadhwa [60], Xu [57] }\end{array}$ \\
\hline Hemodialysis & Yes & Agraharkar [63], Babamohammadi [62] \\
\hline $\begin{array}{l}\text { Pre-dialysis \& } \\
\text { Dialysis }\end{array}$ & Partially & Wilde [64] \\
\hline \multicolumn{3}{|c|}{$\begin{array}{l}\text { Q10: Did the study attempt to balance the allocation between the groups or match groups (e.g., through stratification, matching, } \\
\text { propensity scores)? }\end{array}$} \\
\hline \multirow{3}{*}{$\begin{array}{l}\text { Peritoneal } \\
\text { Dialysis }\end{array}$} & Yes & Castrale [48], Lobbedez [51,52], Oliver [53], Verger [56], Xu [57] \\
\hline & No & Hsieh [49], Lobbedez [50], Oliver [54], Verger [55] \\
\hline & Not Applicable & Brunier [58], Franco [59], Ponferrada [61], Wadhwa [60] \\
\hline \multirow[t]{2}{*}{ Hemodialysis } & Yes & Babamohammadi [62] \\
\hline & Not Applicable & Agraharkar [63] \\
\hline $\begin{array}{l}\text { Pre-dialysis \& } \\
\text { Dialysis }\end{array}$ & Not Applicable & Wilde [64] \\
\hline \multicolumn{3}{|c|}{$\begin{array}{l}\text { Q11: Were important confounding variables taken into account in the design and/or analysis (e.g., through matching, stratification, } \\
\text { interaction terms, multivariate analysis, or other statistical adjustment such as instrumental variables)? }\end{array}$} \\
\hline \multirow{2}{*}{$\begin{array}{l}\text { Peritoneal } \\
\text { Dialysis }\end{array}$} & Partially & Castrale [48], Franco [59], Hsieh [49], Lobbedez [51,52], Oliver [53], Verger [56], Xu [57] \\
\hline & No & Brunier [58], Lobbedez [50], Oliver [54], Ponferrada [61], Verger [55], Wadhwa [60] \\
\hline \multirow[t]{2}{*}{ Hemodialysis } & Yes & Babamohammadi [62] \\
\hline & No & Agraharkar [63] \\
\hline $\begin{array}{l}\text { Pre-dialysis \& } \\
\text { Dialysis }\end{array}$ & No & Wilde [64] \\
\hline
\end{tabular}

Based on studies with pertinent information, patients in Canada [53,54] were offered 14 visits per week for help with their PD exchanges and for the provision of clinical and social support. These patients received, on average, 5.8 visits per week during the first year of their dialysis [53]. In a USA program, a routine visit to a new PD patient was carried out to ensure proper installation of the cycler for an effective dialysis and non-routine visits were made only on an as-needed basis [61]. In this program, a visit took approximately four hours. Another USA program focused on ESRD patients with multiple medical and social problems [60]. In this program, a visit to help patients with their PD exchanges and to provide clinical and social support took, on average, 13 hours. In a HD study from Iran, the $\mathrm{HC}$ intervention was designed to conduct one visit per week before the HD schedule for clinical support and retraining [62].

\section{Outcomes}

\section{Peritoneal dialysis}

While most of the PD studies focused on outcomes related to PD treatment (Table 2), a few provided insights into how the availability of assisted PD offers a choice to patients who are unable to perform their RRT independently. A description of the PD population in France [55], where healthcare system supports nurse assisted PD, revealed that $45 \%$ of all $\mathrm{PD}$ patients and $87 \%$ of those over 90 years of age were assisted by a nurse. Studies have 
shown that the availability of nurse assisted PD increases the eligibility for PD among elderly patients [53] and improved the uptake of PD in general [50]. One study [54] emphasized the importance of the availability of family assistance for $\mathrm{PD}$ utilization even in regions where $\mathrm{HC}$ assisted PD is available.

In PD studies with comparators, outcomes such as peritonitis rate and technique and patient survival constituted the main areas of focus. In general PD populations, studies using information from RDPLF concluded that technique failure/transfer to HD was lower among $\mathrm{HC}$ (nurse) assisted PD patients when compared to self care PD patients only [51,52] and to self care PD and family assisted PD patients as a group [51]. Another study in general PD populations [57], where homeassistants who were not required to have a background in healthcare helped PD patients, found that the probability of technique survival times were similar between HC assisted PD and family assisted PD patients. Studies that focused on elderly concluded that the probability of technique failure was similar between $\mathrm{HC}$ (nurse) assisted PD patients and comparators including patients on self care PD [48] and traditional modalities (i.e., self care PD and in-center HD) [53]. The probability of technique failure following an episode of peritonitis was also similar between home-assistant assisted PD and self care PD and family assisted PD patients [49].

Peritonitis rate was another outcome examined in PD studies with comparators. In almost all of these studies, $\mathrm{HC}$ assisted PD patients and the comparators (including family assisted PD among general PD populations [57], self care PD among elderly [48] and self care PD and family assisted PD among elderly [49]) had similar probabilities of being peritonitis free. In one study [52], HC assisted PD patients had lower peritonitis rates when compared to self care PD. In another study [56], HC assisted PD patients had higher peritonitis rates when compared to family assisted PD patients. However, the difference in peritonitis rates observed in the latter study disappeared when the effects of regular nurse visits from dialysis centers to the $\mathrm{HC}$ assisted PD patients were taken into consideration.

Most of the PD studies with comparators that examined patient survival found a higher probability of mortality among $\mathrm{HC}$ assisted PD patients. This result continued to hold across different comparators including self care PD among general PD populations [51,52], self care PD and family assisted PD among general PD populations [51], family assisted PD among general PD populations [57], and self care PD among elderly PD populations [48]. Two studies about elderly populations were exceptions. In the first study, the risk of mortality did not differ between patients receiving nurse assisted PD and those on traditional modalities [53]. In the second study, peritonitis-related mortality was similar among home-assistant assisted PD and self care PD and family assisted PD patients [49].

The PD studies without comparators focused on varying outcomes such as identifying critical elements of a home visit [61] and exploring costs of RRTs [58]. The studies that considered PD patients with severe disability reported peritonitis rates that ranged from 1 episode per 13.0 patient-months [60] to 20.1 patient-months [58] and hospitalization rates that ranged from 1 admission per 6.0 patient-months [60] to15.3 patient-months [58]. A recent study from Brazil [59] found 1 peritonitis episode per 37.0 patient-months and $60 \%$ patient survival at one year among a general PD population.

\section{Hemodialysis}

The HD study with a comparator [62] concluded that patients in $\mathrm{HC}$ group had improved on 15 of the 19 outcomes considered (including decreases in nausea, vomiting, headache, bone pain, weakness and fatigue and itching and improvements in general condition and the levels of creatinine, potassium and phosphorus of the blood). The HD study without a comparator [63] focused on patients diagnosed with terminal illness and found that, on average, patients were hospitalized for 9.43 days.

\section{Pre-dialysis and dialysis}

Based on survey results, more than three-fourths of PD and HD patients were very satisfied with the pre-dialysis and dialysis phase of their care after the implementation of $\mathrm{HC}$ program [64]. The HC team consisting of three nurses and one renal care assistant provided continuous social support to patients. The $\mathrm{HC}$ team also collected information about patients' life goals and provided information to them about their dialysis modalities.

\section{Risk of bias and confounding}

While most studies had low risk of bias in many domains (Table 3), apart from two studies $[51,52]$ that used imputations techniques for missing information, loss to follow-up was rarely discussed. Some of the studies [48,49,51-53,56,57] have taken into consideration confounding variables such as age and Charlson Comorbidity Index (CCI). The CCI summarizes the impact comorbid conditions have on survival by assigning higher weights to more severe coexisting conditions such as metastatic carcinoma and lower weights to less severe ones such as dementia [65-67]. While CCI is one of the most widely used risk adjustment techniques in observational studies, the characteristics of CKD populations may require multidimensional prognostic indices that take into account physical, psychological, cognitive, functional and social factors [68]. One of the studies included in this SR reported on the physical performance of patients using Karnofsky 
Scale in addition to providing information on their comorbidity scores [59]. Apart from the descriptive information incorporated in the latter study, there were no studies that incorporated multidimensional indices as another confounding variable in their analysis.

\section{Discussion}

Our SR revealed that most of the studies that examined the impact of $\mathrm{HC}$ services among CKD patients focused on dialysis patients, in general, and PD patients, in particular. Among RRTs, assisted PD provides an option for ESRD patients who prefer home-based dialysis therapies but have barriers to self care including physical disability and cognitive impairment. HC assisted PD becomes especially valuable for ESRD patients with additional barriers to self care such as social isolation. The current increases in the prevalence of elderly ESRD patients partly explain the greater emphasis placed on assisted $\mathrm{PD}$ in the CKD HC literature.

The HC assisted PD studies incorporated in this review mostly underscored clinically relevant outcomes for $\mathrm{PD}$ such as peritonitis rate and technique and patient survival. The findings show that technique survival and peritonitis rates for $\mathrm{HC}$ assisted $\mathrm{PD}$ patients were at least similar to or better than those for self care PD and family assisted PD patients. The studies that found better technique survival $[51,52]$ and peritonitis rates [52] for $\mathrm{HC}$ (nurse) assisted PD patients relied on national level French registry using the same time period. The availability of $\mathrm{HC}$ assisted PD may reduce the likelihood of adverse events by improving patient's psycho-social status and supporting them in adhering to the basic principles of PD including peritonitis prevention. Further studies are needed to examine if favorable outcomes continue to hold for $\mathrm{HC}$ assisted PD patients in different regions across the world.

Most PD studies found a higher probability of mortality among $\mathrm{HC}$ assisted PD patients when compared to self care PD or family assisted PD. These studies indicated that patients in their $\mathrm{HC}$ assisted $\mathrm{PD}$ group were older and had higher levels of comorbidities as captured by the CCI. The higher probability of mortality among $\mathrm{HC}$ assisted PD patients persisted in studies that controlled for age and CCI differences across groups. The authors mostly attributed this finding to data insufficiencies in capturing disabilities among PD populations. Apart from one study [59] that described comorbidity and physical performance in their study population, there were no studies that incorporated multidimensional indices that take into account physical, psychological, cognitive, functional and social factors as another confounding variable in their analysis.

The studies included in this SR provided limited information about the characteristics of the $\mathrm{HC}$ interventions. In general, technical requirements imposed on $\mathrm{HC}$ intervention based on the dialysis type used are well known among the CKD community. Additional studies that consider $\mathrm{HC}$ interventions with varying scope and frequency and duration of visits in different CKD populations will provide helpful information to the CKD community, especially for those who are considering $\mathrm{HC}$ programs for their own clinic/practice.

One of the gaps in the literature that was identified by our SR is related to the provision of $\mathrm{HC}$ services among non-ESRD CKD populations. Apart from one study [64] that incorporated information about patient experiences with the implementation of a $\mathrm{HC}$ program that affected both the dialysis and pre-dialysis phases of their care, there were no studies that explored the impact $\mathrm{HC}$ has on non-ESRD CKD populations. It is well known that CKD is often accompanied by several comorbid conditions, is common among older people and its prevalence increases with age. As emphasized by the World Kidney Day 2014 Steering Committee [69], these characteristics of CKD coupled with increased life expectancy worldwide call for further explorations into ways of optimizing health for elderly populations. The impact different $\mathrm{HC}$ services might have in improving health among nonESRD CKD patients is one such area that deserves further explorations.

The lack of studies on the impact home palliative care has on patients with CKD is another gap in the literature that was identified by our SR. The quality of life considerations for CKD patients who are at the advance stages of their disease require focus on several issues including the management of their physical and psycho-social symptoms and the development of an advanced care plan that sets the goals for their care [70-74]. Studies that examine the impact home palliative care has on patients with CKD who are at the advance stages of their disease will help further advance the integration of palliative and renal care.

Our SR identified other gaps in the literature. There were no studies about $\mathrm{HC}$ provision among kidney transplant patients. Studies related to $\mathrm{HC}$ provision among HD patients were limited to small samples.

The $\mathrm{HC}$ interventions incorporated in the CKD literature were mostly limited to nursing care for ESRD patients. There were no studies about the provision of home support for activities of daily living or respite care for caregivers of CKD patients. While HC may become more important as CKD severity increases and, in the case of ESRD, it may be most useful for patients on home-based dialysis modalities or for those who choose conservative care, further studies are needed to quantify these differing levels of $\mathrm{HC}$ use and its impact.

One of the strengths of our study is the comprehensive SR conducted on a topic where there were, to the best of our knowledge, no previous SR undertaken. The 
comprehensive electronic database searches coupled with hand searches and expert consultations resulted in the identification of several gaps in the literature.

Our study has several limitations. One of the limitations of our study is arising from the subject matter itself. $\mathrm{HC}$, as encompassing a diverse set of medical and psycho-social services, is one of the health services research areas that are constantly evolving with limited standardization in terminology. Our study which focused on the intersection of home care with CKD faced additional challenges given the changes in CKD definition itself in the past years that is continuing through today [75]. We made an attempt to balance this fundamental limitation by conducting comprehensive database searches, extensive hand searches and expert consultations. Second limitation of our study is the layered approached followed in study selection. Third limitation is the focus on studies published in English. Given the diversity of $\mathrm{HC}$ services, resource and time considerations were crucial factors in our decision to follow a layered study selection approach and to focus on studies published in English. As indicated above, we made an attempt to balance these limitations by conducting comprehensive database searches, extensive hand searches and expert consultations. Another limitation is our inability to conduct a meta-analysis for our study. The diversity of patient populations, HC interventions and outcomes studied made it impossible to conduct a meta-analysis.

\section{Conclusions}

In this era of aging world population and medical and technical advances, chronic diseases, such as CKD, are growing in incidence and prevalence. HC may be useful in providing a more efficient and higher quality care for CKD patients. However, a synthesis of evidence on the effects of HC among CKD patients has not been undertaken. Our SR, which aimed at filling this void, revealed that extant studies almost exclusively focused on nurse assisted HC patients examining mostly PD related clinical outcomes. Our study concluded that there are several gaps in the literature. Specifically, there were no studies in areas such as home support for activities of daily living, palliative care at home or respite care for caregivers of CKD patients, in general, or for ESRD patients, in particular.

\section{Appendix}

\section{MEDLINE Search Strategy:}

1. exp kidney diseases/

2. exp renal replacement therapy/

3. ((kidney or renal) adj2 (disease* or failure or damage or insufficiency)).mp.
4. ((kidney or renal) adj2 (transplant $* 5$ or dysfunction or therap*)).mp.

5. (dialysis or dialyses or haemodialysis).mp.

6. Kidney, Artificial/

7. (kidney" adj artificial).mp.

8. or/1-7 (540012)

9. exp home care services/

10. (domiciliary adj3 (care or service\$ or nurs\$)).mp.

11. "home nurs $\$ 3$ ".mp.

12. ((home or care) adj3 (nonprofession\$ or nonprofessional\$)).mp.

13. (homemaker adj3 service\$).mp.

14. (home adj3 service\$).mp.

15. "home care".mp.

16. (home adj3 (renal or dialys $\$ 3$ or hemodialy $\$ 3$ or peritoneal)).mp.

17. ((parenteral or nutrition or feeding) adj home).mp.

18. ("hospital at home" or "hospital in the home" or "in-home care").mp.

19. "home health care".mp.

20. (Home adj3 (rehabilitation or occupational or physical or physiotherap\$ or social worker\$ or speech)).mp.

21. Day Care/

22. (palliative adj5 home).mp.

23. ((caregiver\$ or care-giver\$ or carer\$) adj3 "respite care").mp.

24. ((long-term or long term) adj3 (home care or home-care)).mp.

25. activities of daily living.sh. and home.tw.

26. (personal care adj3 home).mp.

27. (self-care adj3 home).mp.

28. (day adj3 care).mp.

29. self care.sh. and home.tw.

30. or $/ 9-29$

31.8 and 30

32. limit 31 to (english language and $y r=" 1990$ -Current")

33. limit 32 to "all child (0 to 18 years)"

34. 32 not 33.

\section{Abbreviations}

CKD: Chronic kidney disease; RRT: Renal replacement therapy; ESRD: End-stage renal disease; HC: Home care; PD: Peritoneal dialysis; HD: Hemodialysis; HHD: Home hemodialysis; SR: Systematic review; KDIGO: Kidney Disease: Improving Global Outcomes; RDPLF: French Language Peritoneal Dialysis Registry; CCl: Charlson Comorbidity Index; CCPD: Continuous cycling PD; CAPD: Continuous ambulatory PD.

Competing interests

The authors declare that they have no competing interests.

\section{Authors' contributions}

SKA contributed to the conception and design, analysis and interpretation of results, and drafted the manuscript. PK contributed to the conception and design, interpretation of results and provided input for manuscript revision. $\mathrm{OD}$ contributed to the interpretation of results and provided input for manuscript revision. AL contributed to the conception and design, 
interpretation of results and provided input for manuscript revision. All authors have read and approved the final manuscript.

\section{Acknowledgements}

This research is supported by an Allied Health Research grant (no.KFOC110022) from the Kidney Foundation of Canada. The authors thank Sharon Stevens for electronic searches. Research assistants Simon Tai, Mithila Makhijani, Thomas Ferguson and Michelle Wong provided excellent support in the earlier phases of this study.

\section{Author details}

${ }^{1}$ School of Population and Public Health, The University of British Columbia and Provincial Health Services Authority, 700-1380 Burrard Street, Vancouver BC V6Z 2H3, Canada. 'Faculty of Medicine, Section of Nephrology, University of Manitoba and Seven Oaks General Hospital, Room 2PD02 - 2300 McPhillips Street, Winnipeg, MB R2V 3M3, Canada. ${ }^{3}$ British Columbia Provincial Renal Agency, Providence Bldg, Room 570.4, 1081 Burrard Street,

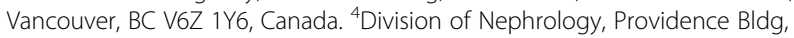
Room 6010A, The University of British Columbia and British Columbia Provincial Renal Agency, 1081 Burrard Street, Vancouver, BC V6Z 1Y6, Canada.

Received: 5 February 2014 Accepted: 19 June 2014

Published: 18 July 2014

\section{References}

1. United Nations, Department of Economic and Social Affairs, Population Division: World Population Prospects: the 2010 Revision, Highlights and Advance Tables. 2011. Working Paper No. ESA/P/WP.220.

2. Canadian Institute for Health Information: Canadian Organ Replacement Register Annual Report: Treatment of end-Stage Organ Failure in Canada, 2000 to 2009. Ottawa: Canadian Institute for Health Information; 2011

3. Zoccali C, Kramer A, Jager KJ: Chronic kidney disease and end-stage renal disease-a review produced to contribute to the report 'Status of health in the European Union: towards a healthier Europe'. NDT Plus 2010, 3:213-224.

4. Davison SN: Pain in hemodialysis patients: prevalence, cause, severity, and management. Am J Kidney Dis 2003, 42(6):1239-1247.

5. Brown EA: Epidemiology of renal palliative care. J Palliat Med 2007, 10(6):1248-1252.

6. Fan SL, Sathick I, McKitty K, Punzalan S: Quality of life of caregivers and patients on peritoneal dialysis. Nephrol Dial Transplant 2008, 23(5):1713-1719.

7. Kurella M, Covinsky KE, Collins AJ, Chertow GM: Octogenarians and nonagenarians starting dialysis in the United States. Ann Intern Med 2007, 146(3):177-183.

8. Cook WL, Jassal SV: Functional dependencies among the elderly on hemodialysis. Kidney Int 2008, 73(11):1289-1295.

9. Weiner DE, Scott TM, Giang LM, Agganis BT, Sorensen EP, Tighiouart $H$, Sarnak MJ: Cardiovascular disease and cognitive function in maintenance hemodialysis patients. Am J Kidney Dis 2011, 58(5):773-781.

10. Brown EA: How to address barriers to peritoneal dialysis in the elderly. Perit Dial Int 2011, 31(Suppl 2):S83-S85.

11. Jager KJ, Korevaar JC, Dekker FW, Krediet RT, Boeschoten EW: The effect of contraindications and patient preference on dialysis modality selection in ESRD patients in the Netherlands. Am J Kidney Dis 2004, 43(5):891-899.

12. Soni RK, Weisbord SD, Unruh ML: Health-related quality of life outcomes in chronic kidney disease. Curr Opin Nephrol Hypertens 2010, 19(2):153-159.

13. Finkelstein FO, Arsenault KL, Taveras A, Awuah K, Finkelstein SH: Assessing and improving the health-related quality of life of patients with ESRD. Nat Rev Nephrol 2012, 8(12):718-724.

14. Pagels AA, Soderkvist BK, Medin C, Hylander B, Heiwe S: Health-related quality of life in different stages of chronic kidney disease and at initiation of dialysis treatment. Health Qual Life Outcomes 2012, 10:71.

15. Canadian Healthcare Association: Home Care in Canada: From the Margins to the Mainstream. Ottawa, Ontario: CHCA; 2009.

16. Prakash S, Perzynski AT, Austin PC, Wu CF, Lawless ME, Paterson JM, Quinn RR, Sehgal AR, Oliver MJ: Neighborhood socioeconomic status and barriers to peritoneal dialysis: a mixed methods study. Clin J Am Soc Nephrol 2013, 8(10):1741-1749.

17. World Health Organization: Active Ageing: A Policy Framework. Geneva: World Health Organization; 2002.
18. Lee H, Manns B, Taub K, Ghali WA, Dean S, Johnson D, Donaldson C: Cost analysis of ongoing care of patients with end-stage renal disease: the impact of dialysis modality and dialysis access. Am J Kidney Dis 2002, 40(3):611-622.

19. McFarlane $\mathrm{PH}$, Pierratos $\mathrm{A}$, Redelmeier DA: Cost savings of home nocturnal versus conventional in-center hemodialysis. Kidney Int 2002, 62:2216-2222.

20. Kroeker A, Clark WF, Heidenheim AP, Kuenzig L, Leitch R, Meyette M, Muirhead N, Ryan H, Welch R, White S, Lindsay RM: An operating cost comparison between conventional and home quotidian hemodialysis. Am J Kidney Dis 2003, 42(Suppl 1):49-55.

21. Komenda P, Chan C, Pauly RP, Levin A, Copland M, Pierratos A, Sood MM: The evaluation of a successful home hemodialysis program: establishing a prospective framework for quality. Clin Nephrol 2009, 71(5):467-474.

22. Dratwa M: Costs of home assistance for peritoneal dialysis: results of a European survey. Kidney Int 2008, 73(Suppl 108s):S72-S75.

23. Grun RP, Constantinovici N, Normand C, Lamping DL: Costs of dialysis for elderly people in the UK. Nephrol Dial Transplant 2003, 18(10):2122-2127.

24. De Vecchi AF, Dratwa M, Wiedemann ME: Healthcare systems and endstage renal disease (ESRD) therapies-an international review: costs and reimbursement/funding of ESRD therapies. Nephrol Dial Transplant 1999, 14(Suppl 6):31-41.

25. Li PK, Cheung WL, Lui SL, Blagg C, Cass A, Hooi LS, Lee HY, Locatelli F, Wang T, Yang CW, Canaud B, Cheng YL, Choong HL, de Francisco AL, Gura V, Kaizu K, Kerr PG, Kuok UI, Leung CB, Lo WK, Misra M, Szeto CC, Tong KL, Tungsanga K, Walker R, Wong AK, Yu AW: Increasing home based dialysis therapies to tackle dialysis burden around the world: a position statement on dialysis economics from the 2 nd Congress of the International Society for Hemodialysis. Nephrology (Carlton) 2011, 16(1):53-56.

26. Collins AJ, Foley RN, Chavers B, Gilbertson D, Herzog C, Johansen K, Kasiske B, Kutner N, Liu J, Peter W, Guo H, Gustafson S: USRDS 2011 annual data report-atlas of chronic kidney disease and end-stage renal disease in the United States: costs of ESRD. Am J Kidney Dis 2012, 59(Suppl 1):e281-e290.

27. Povlsen JV, Ivarsen P: Assisted automated peritoneal dialysis (AAPD) for the functionally dependent and elderly patient. Perit Dial Int 2005, 25(Suppl 3):S60-S63.

28. Smyth A, McCann E, Redahan L, Lambert B, Mellotte GJ, Wall CA: Peritoneal dialysis in an ageing population: a 10-year experience. Int Urol Nephrol 2012, 44(1):283-293.

29. Cheng CH, Shu KH, Chuang YW, Huang ST, Chou MC, Chang HR: Clinical outcome of elderly peritoneal dialysis patients with assisted care in a single medical center - a 25-year experience. Nephrology (Carlton) 2013, 18(6):468-473.

30. Jagose JT, Afthentopoulos IE, Shetty A, Oreopoulos DG: Successful use of continuous ambulatory peritoneal dialysis in octogenarians. Adv Perit Dial 1996, 12:126-131.

31. Szeto CC, Kwan BC, Chow KM: Peritonitis risk for older patients on peritoneal dialysis. Perit Dial Int 2008, 28(5):457-460.

32. Sunder S, Taskapan H, Jojoa J, Krishnan M, Khandelwal M, Izatt S, Chu M, Subramanian P, Chinthalapalli H, Lobbedez T, Jassal SV, Bargman JM, Oreopoulos DG: Chronic peritoneal dialysis in the tenth decade of life. Int Urol Nephrol 2004, 36(4):605-609.

33. Castro MJ, Celadilla O, Munoz I, Martinez V, Minguez M, Auxiliadora Bajo M, del Peso G: Home training experience in peritoneal dialysis patients. EDTNA ERCA J 2002, 28(1):36-39.

34. Ozturk S, Yucel L, Guvenc S, Ekiz S, Kazancioglu R: Assessing and training patients on peritoneal dialysis in their own homes can influence better practice. J Ren Care 2009, 35(3):141-146.

35. Russo R, Manili L, Tiraboschi G, Amar K, De Luca M, Alberghini E, Ghiringhelli $P$, De Vecchi A, Porri MT, Marinangeli G, Rocca R, Paris $V$, Ballerini L: Patient re-training in peritoneal dialysis: why and when it is needed. Kidney Int 2006, 70(Suppl 103s):S127-S132.

36. Bernardini J, Nagy M, Piraino B: Pattern of noncompliance with dialysis exchanges in peritoneal dialysis patients. Am J Kidney Dis 2000, 35(6):1104-1110.

37. Tennankore KK, Kim SJ, Chan CT: The feasibility of caregiver-assisted home nocturnal hemodialysis. Nephron Clin Pract 2012, 122(1-2):17-23.

38. Cohen LM, Germain M, Poppel DM, Woods A, Kjellstrand CM: Dialysis discontinuation and palliative care. Am J Kidney Dis 2000, 36(1):140-144.

39. Smith C, Da Silva-Gane M, Chandna S, Warwicker P, Greenwood R, Farrington $K$ : Choosing not to dialyse: evaluation of planned non-dialytic management in a cohort of patients with end-stage renal failure. Nephron Clin Pract 2003, 95(2):C40-c46. 
40. Chandna SM, Da Silva-Gane M, Marshall C, Warwicker P, Greenwood RN, Farrington K: Survival of elderly patients with stage 5 CKD: comparison of conservative management and renal replacement therapy. Nephrol Dial Transplant 2011, 26(5):1608-1614.

41. Chater S, Davison SN, Germain MJ, Cohen LM: Withdrawal from dialysis: a palliative care perspective. Clin Nephrol 2006, 66(5):364-372

42. Yong DS, Kwok AO, Wong DM, Suen MH, Chen WT, Tse DM: Symptom burden and quality of life in end-stage renal disease: a study of 179 patients on dialysis and palliative care. Palliat Med 2009, 23(2):111-119.

43. Tully P, Saint-Pierre E: Downsizing Canada's hospitals, 1986/87 to 1994/95. Health Rep 1997, 8(4):33-39.

44. Levey AS, Eckardt KU, Tsukamoto Y, Levin A, Coresh J, Rossert J, De Zeeuw D, Hostetter TH, Lameire N, Eknoyan G: Definition and classification of chronic kidney disease: a position statement from Kidney Disease: Improving Global Outcomes (KDIGO). Kidney Int 2005, 67(6):2089-2100.

45. Health Canada: Home care in Canada 1999: an overview. [http://www. hc-sc.gc.ca/hcs-sss/pubs/home-domicile/1999-home-domicile/index-eng.php]

46. Canadian Home Care Association: Making Connections: Sharing Knowledge and Building Communities, 2009, a Year in Review. Mississauga, Ontario: CHCA; 2010

47. Viswanathan M, Berkman ND, Dryden DM, Hartling L: Assessing Risk of Bias and Confounding in Observational Studies of Interventions or Exposures: Further Development of the RTI Item Bank. Methods Research Report. (Prepared by RTI-UNC Evidence-Based Practice Center Under Contract No. 290-200710056-I). 2013/09/06 edn. Rockville, MD: Agency for Healthcare Research and Quality; 2013.

48. Castrale C, Evans D, Verger C, Fabre E, Aguilera D, Ryckelynck JP, Lobbedez T: Peritoneal dialysis in elderly patients: report from the French Peritoneal Dialysis Registry (RDPLF). Nephrol Dial Transplant 2010, 25(1):255-262.

49. Hsieh CY, Fang JT, Yang CW, Lai PC, Hu SA, Chen YM, Yu CC, Tian YC, Chien CC, Hung CC: The impact of type of assistance on characteristics of peritonitis in elderly peritoneal dialysis patients. Int Urol Nephrol 2010, 42(4):1117-1124

50. Lobbedez T, Moldovan R, Lecame M, Hurault de Ligny B, El Haggan W, Ryckelynck JP: Assisted peritoneal dialysis. Experience in a French renal department. Perit Dial Int 2006, 26(6):671-676.

51. Lobbedez T, Verger C, Ryckelynck JP, Fabre E, Evans D: Is assisted peritoneal dialysis associated with technique survival when competing events are considered? Clin J Am Soc Nephrol 2012, 7(4):612-618.

52. Lobbedez T, Verger C, Ryckelynck JP, Fabre E, Evans D: Outcome of the sub-optimal dialysis starter on peritoneal dialysis. Report from the French Language Peritoneal Dialysis Registry (RDPLF). Nephrol Dial Transplant 2013, 28(5):1276-1283.

53. Oliver MJ, Quinn RR, Richardson EP, Kiss AJ, Lamping DL, Manns BJ: Home care assistance and the utilization of peritoneal dialysis. Kidney Int 2007, 71(7):673-678

54. Oliver MJ, Garg AX, Blake PG, Johnson JF, Verrelli M, Zacharias JM, Pandeya S, Quinn RR: Impact of contraindications, barriers to self-care and support on incident peritoneal dialysis utilization. Nephrol Dial Transplant 2010, 25(8):2737-2744

55. Verger C, Ryckelynck JP, Duman M, Veniez G, Lobbedez T, Boulanger E, Moranne O: French peritoneal dialysis registry (RDPLF): outline and main results. Kidney Int 2006, 70(Suppl 103s):S12-S20.

56. Verger C, Duman M, Durand PY, Veniez G, Fabre E, Ryckelynck JP: Influence of autonomy and type of home assistance on the prevention of peritonitis in assisted automated peritoneal dialysis patients. An analysis of data from the French Language Peritoneal Dialysis Registry. Nephrol Dial Transplant 2007, 22(4):1218-1223.

57. Xu R, Zhuo M, Yang Z, Dong J: Experiences with assisted peritoneal dialysis in China. Perit Dial Int 2012, 32(1):94-101.

58. Brunier G, Gray B, Coulis N, Savage J, Manuel A, McConnell H, Mildon B, Sherlock AM: The use of community nurses for home peritoneal dialysis: is it cost-effective? Perit Dial Int 1996, 16(Suppl 1):S479-S482.

59. Franco MR, Fernandes N, Ribeiro CA, Qureshi AR, Divino-Filho JC, da Gloria LM: A Brazilian experience in assisted automated peritoneal dialysis: a reliable and effective home care approach. Perit Dial Int 2013, 33(3):252-258

60. Wadhwa NK, Suh H, Cabralda T, Sokol E, Sokunbi D, Solomon M: Peritoneal dialysis with trained home nurses in elderly and disabled end-stage renal disease patients. Adv Perit Dial 1993, 9:130-133.
61. Ponferrada L, Prowant BF, Schmidt LM, Burrows LM, Satalowich RJ, Bartelt C: Home visit effectiveness for peritoneal dialysis patients. ANNA J 1993, 20(3):333-336.

62. Babamohammadi $\mathrm{H}$, Khalili $\mathrm{H}$ : Effect of a confined program of home-care on the health status of patients receiving hemodialysis. Acta Med Iran 2006, 44(1):28-32.

63. Agraharkar M, Barclay C, Agraharkar A: Staff-assisted home hemodialysis in debilitated or terminally ill patients. Int Urol Nephrol 2002, 33(1):139-144.

64. Wilde C, Macefield J: Improvement in care: a collaborative approach to rehabilitation. EDTNA ERCA J 2001, 27(2):69-71.

65. Charlson ME, Pompei P, Ales KL, MacKenzie CR: A new method of classifying prognostic comorbidity in longitudinal studies: development and validation. J Chronic Dis 1987, 40(5):373-383.

66. Deyo RA, Cherkin DC, Ciol MA: Adapting a clinical comorbidity index for use with ICD-9-CM administrative databases. J Clin Epidemiol 1992 45(6):613-619.

67. Hemmelgarn BR, Manns BJ, Quan H, Ghali WA: Adapting the Charlson Comorbidity Index for use in patients with ESRD. Am J Kidney Dis 2003, 42(1):125-132.

68. Pilotto A, Panza F, Sancarlo D, Paroni G, Maggi S, Ferrucci L: Usefulness of the multidimensional prognostic index (MPI) in the management of older patients with chronic kidney disease. J Nephrol 2012, 25(Suppl 19):S79-S84.

69. Tonelli M, Riella M: Chronic kidney disease and the ageing population. Intern Med J 2014, 44(3):213-217.

70. Davison SN: Integrating palliative care for patients with advanced chronic kidney disease: recent advances, remaining challenges. J Palliat Care 2011, 27(1):53-61.

71. Kurella Tamura M, Cohen LM: Should there be an expanded role for palliative care in end-stage renal disease? Curr Opin Nephrol Hypertens 2010, 19(6):556-560.

72. Hussain JA, Russon L: Supportive and palliative care for people with end-stage renal disease. Br J Hosp Med (Lond) 2012, 73(11):640-644.

73. Cohen LM, Moss AH, Weisbord SD, Germain MJ: Renal palliative care J Palliat Med 2006, 9(4):977-992.

74. Levy JB, Chambers EJ, Brown EA: Supportive care for the renal patient. Nephrol Dial Transplant 2004, 19(6):1357-1360.

75. Pugliese G, Solini A, Bonora E, Orsi E, Zerbini G, Fondelli C, Gruden G, Cavalot F, Lamacchia O, Trevisan R, Vedovato M, Penno G: Distribution of cardiovascular disease and retinopathy in patients with type 2 diabetes according to different classification systems for chronic kidney disease: a cross-sectional analysis of the renal insufficiency and cardiovascular events (RIACE) Italian multicenter study. Cardiovasc Diabetol 2014, 13(1):59.

doi:10.1186/1471-2369-15-118

Cite this article as: Aydede et al:: Chronic kidney disease and support provided by home care services: a systematic review. BMC Nephrology 2014 15:118

\section{Submit your next manuscript to BioMed Central and take full advantage of:}

- Convenient online submission

- Thorough peer review

- No space constraints or color figure charges

- Immediate publication on acceptance

- Inclusion in PubMed, CAS, Scopus and Google Scholar

- Research which is freely available for redistribution 